\title{
The relationship between Sofosbovir / Daclatasvir and some risk factors of stroke
}

EL YAZAL R. ${ }^{1}$ SAYED S. ${ }^{1}$, GOMAA,A. ${ }^{2}$ TAHA, ${ }^{1}$

1:Neurology Department,Faculty of Medicine,Fayoum University,Egypt.

2:Hepatology and Gastroenterology Department ,Faculty of

Medicine,Fayoum University,Egypt.

Corresponding author: Prof Sayed Sobhy Sayed

Email address :Sayedbadawy@gmail.com

\section{Abstract}

stroke is acute neurological deficit result from acute focal injury of central nervous system due to vascular cause as cerebral infarction. Aim of the Work: To investigate the relationship between (Sofosbovir and Daclatasvir) and some risk factors of stroke. The study was conducted in Fayoum General hospital Virology Unite Fifty HCV positive patients who will receive (Sofosbovir and Daclatasvir) as treatment for HCV for 3 months, were included. They were subjected before start of treatment to laboratory assessment as CBC, $\mathrm{HgbA1C}$ and measurement of carotid intimal medial thickness by carotid Duplex was done. Follow up the patients3monthes after end of treatment by the same laboratory and radiological assessment. Fifty matched healthy volunteers were recruited as controls. Our results show statistically significant higher carotid IMT after treatment compared to before treatment. There is positive correlation between mean IMT and mean TLC and HGBA1C.

\section{Keywords:}

Stroke, HCV, Directly acting antiviral, Carotid intimal medial thickness

\section{Introduction}

Stroke is defined as a neurological deficit due to an acute focal insult of the central nervous system (CNS) by a vascular etiology, including cerebral infarction, subarachnoid hemorrhage and intra-cerebral hemorrhage (ICH), and is the main etiology of disability and death in the whole world. Stroke is defined according to the recent definition of WHO as rapidly developing clinical signs of focal (or global) disturbance of cerebral function with no evident etiology other than that of vascular cause (Easton JD et al., 2009). 
Hepatitis $\mathrm{C}$, a hepatic disease caused by the hepatitis $\mathrm{C}$ virus (HCV), can range in severity from a mild illness, lasting a few weeks, to a serious condition that can lead to chronic liver disease, liver cirrhosis, and hepatocellular carcinoma. Worldwide, it is estimated that 350,000 people die every year from hepatitis $\mathrm{C}$ disease complications (WHO Hepatitis C. Fact, 2013).

Chronic hepatitis $\mathrm{C}$ virus (HCV) infection causes the frequent association between liver and extrahepatic disorders. HCV tropism for lymphoid cells may contribute to poly-oligoclonal B-lymphocyte expansion that results in the production of different autoantibodies and immuno-complexes, such as mixed cryoglobulins (CGs) that are commonly observed in a high proportion in $\mathrm{HCV}$ infected patients (Zignego et al., 2017).

Many new therapies in preclinical or clinical development act on targets in the viral life cycle to directly inhibit viral production. These drugs, which are known as specifically targeted antiviral therapy for hepatitis $\mathrm{C}$ or direct-acting antiviral (DAA) agent (Jazwinski, A.B et al., 2011).

\section{Patients and Methodes}

The present study is a prospective case control study that was enrolled in the Fayoum University Hospitals. Patients were recruited from the Virology Unit of Fayoum General Hospital in the period from November 2019 to June 2020.

The study included 50 patients who were $\mathrm{HCV}$ positive adults and 50 controls who were the patients' relatives. Both groups were matching in age and sex .All patients were subjected to full history, HgbA1C,TLC, Carotid Duplex ,General and Neurological Examination for patients before treatment and 3 monthes after the end of treatment and for controls. 


\section{Results}

Table (1)

\begin{tabular}{|c|c|c|c|c|c|}
\hline Variables & \multicolumn{2}{|c|}{ Before $(\mathbf{N = 5 0 )}$} & \multicolumn{2}{c|}{ After $(\mathbf{N = 5 0 )}$} & p-value \\
\hline IMT & Median & Range & Median & Range & p-value \\
\hline Right side CCA & 0.075 & $0.03-0.9$ & 0.10 & $0.03-0.7$ & $<0.001^{* *}$ \\
\hline Left side CCA & 0.070 & $0.04-0.8$ & 0.10 & $0.02-1.3$ & $0.003^{*}$ \\
\hline Mean IMT & 0.075 & $0.035-0.85$ & 0.10 & $0.025-0.8$ & $0.04^{*}$ \\
\hline
\end{tabular}

Our study shows higher IMT of common carotid arteries on both right and left sides after treatment compared to before treatment with statistically significant difference as shown in Table1. 
Table (2)

\begin{tabular}{|c|c|c|c|}
\hline \multirow{2}{*}{\multicolumn{2}{|c|}{ Variables }} & \multicolumn{2}{|c|}{ Mean IMT } \\
\hline & & $\mathbf{R}$ & p-value \\
\hline \multicolumn{2}{|c|}{ Age (years) } & 0.18 & 0.06 \\
\hline \multicolumn{2}{|c|}{ BMI $\left(\mathrm{Kg} / \mathrm{m}^{2}\right)$} & 0.17 & 0.08 \\
\hline \multirow{5}{*}{$\begin{array}{c}\text { Laboratory } \\
\text { investigations }\end{array}$} & INR & 0.15 & 0.1 \\
\hline & Uric acid & -0.09 & 0.4 \\
\hline & PLT & 0.04 & 0.7 \\
\hline & FBS & 0.14 & 0.2 \\
\hline & $\mathrm{HbA1c}$ & 0.20 & $0.04 *$ \\
\hline \multirow{5}{*}{ Lipid profile } & TLC & 0.29 & $0.004 * *$ \\
\hline & Cholesterol & 0.01 & 0.9 \\
\hline & Triglyceride & -0.13 & 0.2 \\
\hline & HDL & -0.04 & 0.7 \\
\hline & LDL & 0.04 & 0.7 \\
\hline
\end{tabular}

Our study shows that there is statistically significant positive correlation between mean IMT and the level of both HbA1c and TLC as shown in Table. On the other hand, there is no statistically significant correlation between mean IMT and other variables.

\section{Discussion}

Our study showed significant increase in carotid IMT after treatment with DAAs which agrees with Ichikawa, T et al. (2019) who reported that IMT values were exacerbated after a year of DAA treatment so atherosclerosis must be evaluated in patients achieving an SVR.

On the contrary, Rezq A et al. (2020) reported no significant change in IMT after end of treatment with DAA. Nevertheless, Petta $S$ et al. (2018) reported a decline in carotid IMT after the end of treatment with DAA. This conflict may be due to 
difference in timing of follow-up measurement of carotid IMT as (Rezq A et al. (2020) measured IMT after end of treatment and Petta $\mathbf{S}$ et al. (2018) measured IMT 12 months after end of therapy and we measured IMT 3 months after end of therapy.

\section{Conclusion}

The DAA treatment (Daclatasvir and Sofosbovir) used in $\mathrm{HCV}$ positive

\section{References}

Easton, J.D., Saver, J.L., Albers, G.W., Alberts, M.J., Chaturvedi, S., Feldmann, E., ... \& Lutsep, H.L. (2009). Definition and evaluation of transient ischemic attack: a scientific statement for healthcare professionals from the American Heart Association/ American Stroke Association Stroke Council; Council on Cardiovascular Surgery and Anesthesia; Council on Cardiovascular Radiology and Intervention; Council on Cardiovascular Nursing; and the Interdisciplinary Council on Peripheral Vascular Disease: the American Academy of Neurology affirms the value of this statement as an educational tool for neurologists. Stroke, 40(6): 2276-2293.

Ichikawa, T., Miyaaki, H., Miuma, S., Motoyoshi, Y., Narita, S., Toda, S., ... \& Hino, N. (2019). Carotid intima-media thickness and small
Our study showed significant relation between carotid IMT and TLC which comes in agreement with TemelkovaKurktschiev, T et al. (2002) who found a highly significant correlation between TLC and both IMT mean and IMTmax of the CCA.

patients made those patients more vulnerable to develop CVS because it is associated with an increase of carotid IMT.

dense low-density lipoprotein cholesterol increase after one year of treatment with direct-acting antivirals in patients with hepatitis $\mathrm{C}$ virus infection. Internal Medicine, 151418.

Jazwinski, A. B. \& Muir, A.J. (2011). Direct-acting antiviral medications for chronic hepatitis $\mathrm{C}$ virus infection. Gastroenterology \& Hepatology, 7(3): Petta, S., Adinolfi, L.E., Fracanzani, A.L., Rini, F., Caldarella, R., Calvaruso, V., ... \& Licata, A. (2018). Hepatitis $C$ virus eradication by direct-acting antiviral agents improves carotid atherosclerosis in patients with severe liver fibrosis. Journal of Hepatology, 69(1): 18-24.154.

Rezq A, Hazem M, Okasha N, Aly M(2020) Safety of Sofosbuvir and Daclatasvir in Patients having Ischemic Heart Disease for Treatment of $\mathrm{HCV}$ Compensated Cirrhosis, American Journal of Biomedical 
Science \& Research ISSN: 26421747.

\section{World Health Organization.}

Hepatitis C. Fact sheet no. 164.

Geneva, Switzerland: World Health

Organization Media Centre; 2013. (Hepatitis C key facts).

Zignego, A.L., Ramos-Casals, M., Ferri, C., Saadoun, D., Arcaini, L.,
Roccatello, D., ... \& Casato, M. (2017). International therapeutic guidelines for patients with $\mathrm{HCV}$ related extrahepatic disorders. A multidisciplinary expert statement. Autoimmunity Reviews, 16(5): 523541. 